\title{
FRATURA CULTURAL: AMÉLIA, DE ANA CAROLINA
}

\section{CULTURAL RUPTURE: AMÉLIA BY ANA CAROLINA}

\author{
Leonardo Francisco Soares ${ }^{1}$ \\ UFU- Universidade Federal de Uberlândia
}

RESUMO: Este artigo examina os processos específicos de construção de identidades no contexto latino-americano. Através do estudo de algumas imagens presentes na narrativa fílmica Amélia (2000), de Ana Carolina, que encena as tensões do encontro entre "Nós e o Outro", investiga-se o modo como a ficção contemporânea problematiza os processos de identificação coletiva possíveis. Articula-se, ainda, o tema da identidade nacional com as concepções de língua, espaço, tradição e história.

PALAVRAS-CHAVE: Narrativa Contemporânea; Cinema; Identidade Nacional; Ana Carolina.

ABSTRACT: This paper examines the specific processes of identity constructions in Latin American context. The aim is to investigate how contemporary fiction questions the possible processes of collective identification through the study of some images present in the filmic narrative Amélia (2000), by Ana Carolina, who enacts the tensions of the encounter between "we and the other". The theme of national identity is also approached along with the conceptions of language, space, tradition and history.

KEYWORDS: Contemporary Narrative; Cinema; National Identity; Ana Carolina.

O guerreiro parou, caiu nos braços Do velho pai, que o cinge contra o peito,

Com lagrimas de júbilo bradando:

"Este, sim, que é meu filho muito amado!

"E pois que o acho enfim, qual sempre o tive,

"Corram livres as lagrimas que choro,

"Estas lágrimas, sim, que não desonram."

Gonçalves Dias, I Juca Pirama

\footnotetext{
${ }^{1}$ Doutor em Letras: Estudos Literários, pela Universidade Federal de Minas Gerais. Atua como professor adjunto do Instituto de Letras e Linguística da Universidade Federal de Uberlândia. É professor permanente do Programa de Pós-Graduação em Letras da mesma universidade. Publicou recentemente o livro Leituras da Outra Europa: guerras e memórias na literatura e no cinema da Europa Centro-Oriental (Editora UFMG, 2012). Tem artigos publicados em diversos periódicos do país, tais como: Machado de Assis em Linha (Fundação casa de Rui Barbosa-RJ/USP); Aletria (UFMG); Cadernos de Língua e Literatura Hebraica (USP), Literatura $e$ Autoritarismo (UFSM); Letras \& Letras (UFU); Caligrama (UFMG). E-mail: <leofs@ileel.ufu.br>
}

Disponível em: http://seer.fclar.unesp.br/casa 
Através do estudo de algumas imagens presentes na narrativa fílmica Amélia (2000), de Ana Carolina, este artigo $^{2}$ investiga o modo como a ficção contemporânea problematiza os processos de identificação coletiva possíveis. Tal reflexão faz parte do desenvolvimento de um projeto de pesquisa mais amplo, intitulado Literatura:Cinema. Agenciamentos e Heterotopias em Narrativas Contemporâneas, que é voltado para o exercício dos estudos literários atrelado à crítica da cultura e à literatura comparada, salientando, em específico, relações intersemióticas entre literatura e cinema. A proposta de "leitura estrábica" - para tomar a noção de Ricardo Piglia - do cinema através dos estudos literários e da discussão que os cerca, aposta na ampliação e complexificação dos métodos de pesquisa para se refletir sobre a teoria literária, enriquecendo, assim, a seara desse campo de estudo. Em outras palavras, é uma tentativa de não atrelar a produção do conhecimento a modos absolutistas e reducionistas de controle dos saberes.

Se, por um lado, o estudo das relações intersemióticas nas artes favorece a mobilidade das fronteiras, o diálogo entre discursos advindos de diferentes espaços epistemológicos, o encontro entre vozes, saberes e sabores variados; por outro, a proliferação desses estudos, muitas vezes, revela obstáculos e dificuldades, colocando novos desafios para a teoria literária. Em primeiro lugar, nas pesquisas que aproximam mais de uma arte, torna-se necessária a competência múltipla; no caso do objeto específico do presente artigo, por exemplo, tanto na área dos estudos literários como naquela dos estudos da arte cinematográfica. Além disso, faz-se necessária a busca de uma terminologia, de operadores teóricos e de uma metodologia adequados aos campos disciplinares em diálogo. A falta de atenção e apuro com esses pontos problemáticos pode levar a aproximações fantasiosas, não fundamentadas por um referencial teórico preciso.

É no âmbito dessas questões, consciente das "dores e delícias" de tal aproximação, que, aqui, propõe-se, como ponto de partida, conforme já anunciado, tomar como objeto de reflexão a narrativa cinematográfica de Ana Carolina sob o viés de um referencial teórico ampliado. Contudo, se a proposta parte de uma perspectiva dual - teoria da literatura e cinema -, o objetivo não é manter qualquer paralisia em abordagens dicotômicas; pelo contrário, ao inserir a reflexão teórica como ponto vital de conexão, pretende-se instalar uma terceira margem móvel, dinâmica e atualizada.

O roteiro do filme Amélia toma como "pré-texto" um fato histórico, a última das três visitas que a atriz francesa Sarah Bernhardt fez ao Brasil em 1905, como parte da turnê que incluía ainda Buenos Aires e Nova York, quando, numa apresentação da peça Tosca, de Victorien Sardou, no Teatro Lírico do Rio de Janeiro, a atriz sofreu um acidente e fraturou a perna. Porém, Amélia não deve ser interpretado simplesmente como um filme biográfico sobre a relação da atriz francesa, a mais famosa de sua época e talvez a mulher mais importante daquele período, com o Brasil. Na verdade, Ana Carolina narra o encontro entre três mulheres de Cambuquira, interior de Minas Gerais, e outra mulher vinda da Europa, que, por uma contingência, é Sarah Bernhardt. A ficção tecida pela cineasta é lúdica e inventiva e, portanto, desmonta, transforma e falseia as fontes. Para retomar as palavras da diretora, o que interessa é a "pororoca cultural" que se estabelece no encontro entre a personagem Sarah Bernhadt e as três mineiras, a intenção é retratar artisticamente o combate

\footnotetext{
${ }^{2}$ Uma primeira versão deste estudo foi apresentada em forma de comunicação na $9^{\text {a }}$ edição das Jornadas Andinas de Literatura Latino Americana -JALLA, realizada em Niterói em Agosto de 2010.

3 "un ojo puesto en la inteligencia europea y el otro puesto en las entrañas de la patria" (PIGLIA. Memoria y tradición. In: CONGRESSO INTERNACIONAL ABRALIC, 2, 1990, Belo Horizonte. Anais.... Belo Horizonte: UFMG, v. 1, 1990, p. 60-66 p. 61). Ver também: PIGLIA. Una propuesta para el nuevo milenio. Margens: caderno de cultura, Belo Horizonte, n.2, p.1-3 out.2001.
} 
entre dois mundos diferentes, sendo que um deles, considerado "civilizado", é quem determinou que a civilização está do lado de lá e a barbárie do lado de cá. (CAROLINA, 2004). Ao voltar-se para uma narrativa fílmica que encena as tensões do contato entre "o Nós e o Outro", este estudo pretende também inserir-se no diálogo com uma vertente da crítica latino-americana que, ao tomar como base discrepâncias históricas, formula um conceito de identidade migrante, em estado de deslocamento, e revestido de um caráter híbrido.

Antes de adentrar na análise do texto fílmico Amélia, propriamente dito, faz-se interessante situar a dimensão histórica e contextual de sua produção. Ana Carolina Teixeira Soares, conhecida no meio cinematográfico apenas pelo primeiro nome composto, ingressou na carreira cinematográfica ainda na década de 1960, época de efervescência do Cinema Novo. A princípio, a cineasta dedicou-se à produção de documentários, sendo que, em 1974, realizou o emblemático Getúlio Vargas, a partir de material coletado do antigo Departamento de Imprensa e Propaganda (DIP), cuja repercussão alcançada permitiu que Ana Carolina alçasse outros voos. Assim, em 1977, dá início à produção de seu cinema de ficção, com Mar de rosas, que será o primeiro da trilogia composta por Das tripas coração (1982) e Sonho de valsa (1987); filmes que propõem um olhar singular sobre o universo feminino e colocam definitivamente o nome da diretora na tradição de um cinema de autoria produzido no Brasil. (Cf. MORCAZEL, 2010).

Treze anos, portanto, separam Amélia (2000) de Sonho de valsa, o filme imediatamente anterior de Ana Carolina. A distância temporal em si não é significativa, singular. Propositalmente, desconsiderando especificidades, algumas conjecturas de ordem criativa poderiam ser aventadas para justificar o intervalo entre as produções: idiossincrasias do processo de criação, indefinição quanto a projetos, perfeccionismo da artista... Por outro lado, tal hiato aponta para um elemento, para o qual todo aquele que se debruça na análise de um texto fílmico deve atentar: o binômio criação e consumo/ arte e indústria. ${ }^{4}$ Ironicamente, uma das perguntas que atravessa a narrativa de Amélia, repetida incessantemente pelas personagens Francisca, Osvalda e Maria Luísa, as matutas de Cambuquira, é "E o dinheiro? Cadê o dinheiro" (AMÉLIA, 2000, cap.5; 8; 10,13 entre outros) ${ }^{5}$ - o dinheiro de Amélia, que assim como a personagem esfuma-se na trama - também é a pergunta que assombrou o projeto de realização do filme nesse intervalo de dez anos.

De 1990, quando aparecem, na imprensa, as primeiras notícias sobre o projeto de Ana Carolina, a 2000, quando o filme é finalmente lançado, muitas coisas aconteceram. Várias versões do roteiro foram escritas, modificações no elenco - cogitaram-se, por exemplo, Catherine Deneuve, Vanessa Redgrave, Irene Papas ou Isabelle Huppert no papel de Sarah Bernhardt -; mudança no título - primeiro era Páscoa em Março, fome e mortaço; depois, somente Páscoa em Março -, tudo em meio a solavancos e modificações sofridas pela "indústria" cinematográfica brasileira, que merecem ser resgatados aqui, pois contribuem para a reflexão sobre os processos específicos de construção de identidades no contexto latinoamericano, ao explicitarem as diferenças entre a produção de cinema em espaços hegemônicos e periféricos.

A partir de março de 1990, data do início do governo de Fernando Collor de Mello, com a extinção da Embrafilme e a revogação de toda a legislação específica do

\footnotetext{
${ }^{4}$ Sobre esse tema, ver: ROSENFELD, Anatol. Cinema: arte \& indústria. In: Cinema: arte \& indústria. São Paulo: Perspectiva, 2002. (Debates), p.33-47.

${ }^{5}$ As citações a trechos do filme seguem as normas NBR 6023 - Informação e documentação - Referências Elaboração - e NBR 10520 - Informação e documentação - Citações em documentos - Apresentação. (Cf. Citando filmes. In: BIBLIOTECA da ECA/USP. Disponível em: < http://bibliotecadaeca.wordpress.com/2011/ 06/16/citando-filmes/>; Acesso em 11 jul. 2012).
} 
audiovisual, assiste-se à quase completa paralisação da produção cinematográfica nacional. No final de 1991, surge a Lei Federal de Incentivo à Cultura, conhecida também como Lei Rouanet. No governo Itamar Franco, em meados de 1992, criou-se uma nova forma de captação de recursos que foi a Lei do Audiovisual, recolocando o Estado, mesmo que de uma maneira indireta, na produção cinematográfica. ${ }^{6}$ Apesar desses "incentivos", o cinema brasileiro ainda persistirá "condenado ao ostracismo" das telas, até que, em janeiro de 1995, Carlota Joaquina - a princesa do Brasil, de Carla Camuratti, ganha as salas de cinema, e passa a ser tomado como marco do que se convencionou chamar de "retomada do cinema brasileiro". A expressão retomada remete à ideia de um movimento, um boom, mas na verdade o que aconteceu foi um estrangulamento da produção, durante os dois anos do governo Collor, resultando num acúmulo de filmes em produção, estagnados nos anos seguintes, que passariam a ser lançados efetivamente a partir de 1995, produzindo uma aparência de boom. (NAGIB, 2002, v. 1, p.34). Enquanto isso, Ana Carolina e seu projeto seguiram uma via-crúcis - a expressão é usada aqui em analogia com a via-crúcis da personagem Teresa no filme Sonho de valsa - até chegar às telas.

Se no início de 1990, a diretora já estabelecera contratos de coprodução com a Embrafilme, a TV Espanhola e a Secretaria de Cultura de São Paulo, a decomposição da empresa estatal levou ao adiamento, por tempo indefinido, do projeto. Com as leis Roanet e do Audiovisual debaixo dos braços, a cineasta partiu em busca de captação de recursos para a realização do filme - a aprovação do projeto na ANCINE data de 1993 e o fim da captação, $1998^{7}$-, que só será finalizado em 2000.

Amélia coloca-se, segundo uma afirmação de Roberto Corrêa dos Santos, como o filme nacional que, nos últimos quinze anos, melhor se voltou para a reflexão cultural mais direta sobre Brasil. Nas palavras do pesquisador:

[...] o ponto mais elevado que se pôde atingir para - e de modo inteiramente já não mais, digamos, moderno - reavivar, por meio da película, a vitalidade crítica (sábia, múltipla e sarcástica) capaz de expor, ao limite e aos borbotões, os sintomas que dirigem a vida 'nossa', no 'Brasil'. (SANTOS, 2002, Disponível em: <http://www.letras.puc-rio.br/catedra/revista/6Sem 10.html>).

Podemos complementar, depois de esboçado o trajeto de sua produção, que o filme de Ana Carolina, para além de ser um filme sobre o Brasil, é também um filme sob o Brasil, submetido às condições de produção impostas por essa condição. O uso do sob é estratégico, pois este é um signo bastante recorrente nas reflexões da cineasta, como atestado em diversas de suas entrevistas. Nesse sentido, é bastante conhecida a afirmação da diretora a respeito de seus filmes Mar de rosas (1978); Das tripas coração (1982) e Sonho de valsa, de que estes não eram apenas filmes sobre a mulher, mas sob a mulher, sob a condição feminina. (cf. CAROLINA, 1987).

\footnotetext{
${ }^{6}$ Sobre a legislação e a produção cinematográfica nacional, ver o estudo: ALMEIDA JR., José Maria G. de. A legislação e o cinema brasileiro. Brasília: Consultoria Legislativa da Câmara dos Deputados, 2001. (Estudos). Disponível em: <http://biblioteca.planejamento.gov.br/biblioteca-tematica-1/textos/educacao-cultura/texto-72013-a-legislacao-e-o-cinema-brasileiro.pdf>; Acesso em: 11 jul. 2012.

Conferir: Documentos da ANCINE, disponíveis em: <http://sif.ancine.gov.br/projetosaudiovisuais/ ConsultaProjetosAudiovisuais.do;jsessionid=56EA4A64E86BE137EEA5FD1D97A59C8F?method=detalharPro jeto\&numSalic=920346>; http://www.ancine.gov.br/media/VALORES_CAPTADOS_MERCADO_1995 2005.pdf; Acesso em: 26 jul. 2010.
}

Disponível em: http://seer.fclar.unesp.br/casa 
Em um texto escrito originalmente em 1988, que trata do cinema de ficção de Ana Carolina, Flora Süssekind salienta que é o exercício de apropriação e crítica do lugarcomum e a explicitação minuciosa e irônica de frases e imagens-feitas, de alguns clichês e convenções que contribuem para cristalizar o senso comum e a norma social brasileira, que têm funcionado como mote de seus filmes:

Há um verdadeiro inventário de provérbios, trechos de canções e textos conhecidos, brincadeiras infantis, slogans, hinos, orações e banalidades que, de tão detalhado, produz uma opacidade e uma comicidade capazes de, à medida mesmo que se multiplicam e são repetidos ou justapostos, tirar deles a impressão que costumam provocar quando ditos isoladamente no cotidiano. $(1998, \text { p.60) })^{8}$

Por esse viés, o título primitivo do filme, Páscoa em março, fome e mortaço, uma pérola da fraseologia popular, em uma primeira leitura, soa mais próximo dos filmes anteriores de Ana Carolina. Por outro lado, a economia e aparente simplicidade do uso do nome próprio "Amélia" pode esconder nuanças. Desde que, em 1942, Mário Lago e Ataulfo Alves compuseram o samba "Ai, que saudades da Amélia", o nome extrapolou a roda de samba e virou mais um fenômeno linguístico da ordem dos clichês, das frases feitas e dos provérbios. O pessoal coadunou-se ao mais impessoal, e Amélia passou a ser sinônimo de mulher amorosa, passiva e serviçal, virando, inclusive, verbete de dicionário. (Cf. AMÉLIA. In: NOVO Aurélio, 1999, p. 119; AMÉLIA. In: HOUAISS, 2001, p.186)

Nesse sentido, o nome próprio presta-se perfeitamente ao inventário de Ana Carolina. No filme homônimo, Amélia é a "fiel camareira" que serve Sarah Bernhadt há 20 anos. Logo na primeira sequência, que funciona como um brevíssimo prólogo do filme, Amélia aparece amparando a diva após uma apresentação teatral na Paris de 1905, para minguada plateia que a ovaciona. Sarah revela-se em crise - sente-se cansada e abandonada pelo seu público -, Amélia a acolhe, ouve suas lamurias e a consola em um francês impecável. Na vida de Sarah, Amélia é "Amélia", símbolo de servilismo, de aceitação e acolhimento, de cessão - em dado momento do filme Sarah Bernhardt afirma: "Amélia era eu". Mesmo quando canta a "Canção do exílio," de Gonçalves Dias, Amélia esmera-se na mímica da Outra (AMÉLIA, 2000, cap.6). Esses versos do poeta maranhense, tomados desde muito tempo como expressão máxima da construção identitária brasileira, insurgem em diferentes momentos do filme sempre associados à figura cordial e europeizada de Amélia, em busca de ascensão e reconhecimento social. Como se verá mais a frente neste texto, Francisca, a primogênita das irmãs de Cambuquira, recuperará não o poema associado a uma identidade conciliatória, mas a revisão radical proposta por "I-Juca Pirama".

Além disso, a forma como a personagem título é construída revela-se bastante significativa também: Amélia quase não está lá. A personagem aparece pulverizada ao longo de toda a trama narrativa, através de flashes brevíssimos que entrecortam o filme inteiro, de modo fantasmático na fala ininterrupta das irmãs de Cambuquira e na memória de Sarah Bernhadt. Além disso, o fato de Amélia ser interpretada por Marília Pêra - cuja participação é dinamitada dentro do filme, o que na época de lançamento do filme causou certo desconforto entre atriz e diretora - funciona como mais uma aresta irônica salpicada no interior da narrativa.

\footnotetext{
${ }^{8}$ SÜSSEKIND, Flora. Paciência e ironia: sobre o cinema de ficção de Ana Carolina. In: A voz e a série. Rio de Janeiro; Belo Horizonte: Sette Letras; UFMG, 1998. p. 59-68. 
Em torno da figura de Amélia, constrói-se o enredo, move-se a ficção. Submissa e, ao mesmo tempo, poderosa, Amélia é o motivo da viagem de Sarah Bernhardt ao Brasil. É uma carta que ela escreve às irmãs de Cambuquira - "os destinos de uma carta" (SANTIAGO, 1992, p. 463); mais uma! - que vai detonar o contato entre elas e a diva francesa. O corte é abrupto. Do camarim, no teatro em Paris, onde Sarah desfalece nos braços de Amélia, o espectador é colocado na perspectiva de Francisca, a primogênita das três cambuquirenses, que caminha pelo espaço desolador da fazenda. Osvalda chega trazendo a carta de Amélia. Também presente a agregada, Maria Luisa - as três de vestes escuras, como também é escuro o espaço da casa; clara, somente a paisagem que invade as janelas e as frestas da porta (AMÉLIA, 2000, cap.1). Ao filmar o cenário rural de Minas Gerais, os planos são longos, a ação rarefeita, as situações se desenvolvem lentamente, como na tradição do cinema brasileiro, fundada por Humberto Mauro e perpetuada pelo cinema novo, em uma homenagem visual a uma tradição de nosso cinema em seu investimento no complexo simbólico do sertão. (GALVÃO, 2004). Transportando para o cinema a noção de "procedimento menos" (estilo pobre) que Haroldo de Campos (1992) lança mão para pensar uma vertente da literatura brasileira, pode-se afirmar que Ana Carolina insere-se aqui em uma vertente do cinema brasileiro que opta pelo tartamudear das palavras e imagens, o estilo pobre, do menos contra o mais, tão bem formulado por Glauber Rocha no texto manifesto "Uma estética da fome".

E é também lentamente, às apalpadelas e tropeços, que se dá a leitura da carta de Amélia, que revela a intenção de não mais viver no Brasil e reivindica a venda das terras em decadência - antes promissoras devido as, como repete com ironia Francisca, "maravilhas das águas curativas." Reflexo da potência de Amélia, da potência do outro - "chegou a hora de dividir o que é nosso... quero a minha parte, sei que vocês não têm dinheiro para se opor à venda." - a carta, em que são vistas como simplórias e atrasadas, detona sentimentos contraditórios nas irmãs. Osvalda vai do desespero a uma autovalorização tardia, devolvendo a Amélia a acusação de inveja: “(...) Inveja da minha coragem de ser assim quem eu sou." Quanto a Francisca, aferra-se no desejo de não vender nem arrendar as terras, de que tudo fique como sempre foi, ao mesmo tempo em que se vê diante de um desejo nunca antes manifesto: “(...) Rezo para que alguma desgraça aconteça a Amélia, para ela não me tirar daqui... Termino a reza agradecendo a Amélia por me tirar daqui." Os conselhos contidos na carta também são sintomáticos: “(...) finjam que entendam (...) é só ficarem caladas." (AMÉLIA, 2000, cap.1). Para Amélia, a negociação só e possível nessa ordem imperativa, a partir de uma perspectiva externa e $s o b$ o artifício do fingimento e da mímica.

Por outro lado, as "matutas" não obedecem, partem, mas levam na bagagem seus utensílios (o urinol, o fogareiro), suas comidas (mandioca, milho), um porco. No primeiro encontro com Sarah, elas jogam-lhe o porco nas mãos. A atriz comprime-o ao corpo e continua, em melodioso francês, o discurso de lamento pela morte de Amélia, à revelia dos grunhidos desesperados do animal. Na verdade, os ruídos, os rumores, a rateação estarão presentes o tempo todo, impedindo a comunicação entre as personagens. Sarah se expressa em francês, sua aia, Vincentine, em francês, espanhol e italiano, as mineiras, em nosso português, ninguém se entende, cria-se um efeito semelhante àquilo que Roland Barthes chama de "balbucio":

O balbucio é uma mensagem duas vezes malograda: por uma parte compreende-se mal; mas, por outra, com esforço, chega-se a compreender apesar de tudo; não está verdadeiramente nem na língua nem fora dela: é um ruído de linguagem comparável à sequência de barulhos pelos quais um motor dá a entender que está mal regulado. (BARTHES, 2004, p.93). 
Emblemática, nesse sentido, é a sequência em que, no palco do teatro, Sarah exige que as três mulheres repitam em francês: "Repita, imbecil! Ate mesmo o talento tem fim!" (AMÉLIA, 2000, cap.10). Todas malograrão com exceção de Francisca, que ao final de uma gradação em que vai construindo novas frases, por meio de desvios, outros sentidos e conotações, até chegar à assertiva em francês: "même le talent est sans fin!" (Até mesmo o talento tem fim!) Antes, surgem "o talento tem fome", "Até tem fome". O "fin" (fim) metamorfoseia-se em "faim" (fome). A fome de Francisca e de Ana Carolina é como a fome de Glauber Rocha formulada em seu famoso manifesto:

\begin{abstract}
A fome latina, por isto, não é somente um sintoma alarmante: é o nervo de sua própria sociedade. Aí reside a trágica originalidade do Cinema Novo diante do cinema mundial: nossa originalidade é nossa fome e nossa maior miséria é que esta fome, sendo sentida, não é compreendida. (...) Nós compreendemos esta fome que o europeu e o brasileiro na maioria não entendeu. Para o europeu, é um estranho surrealismo tropical (...) Sabemos nós - que fizemos estes filmes feios e tristes, estes filmes gritados e desesperados onde nem sempre a razão falou mais alto - que a fome não será curada pelos planejamentos de gabinete e que os remendos do tecnicolor não escondem, mais agravam seus tumores. Assim. somente uma cultura da fome, minando suas próprias estruturas, pode superar-se qualitativamente: e a mais nobre manifestação cultural da fome é a violência. (1979, p. 16-17)
\end{abstract}

A cena desdobra-se para uma luta de esgrimas, entre a atriz francesa e a matriarca das irmãs de Minas, que parece ininterrupta. Num dado momento Francisca grita: "Com é que faz pra parar ela?" A luta parece que não irá cessar, até que Francisca impõe-se pela violência revolucionária da linguagem ao bradar em francês berrado: "Até mesmo o talento tem fim!"; Sarah queda-se, vencida. O desconcerto das línguas é a tônica de todo o filme. Em uma cena imediatamente anterior (AMÉLIA, 2000, cap.9), tem-se presentada a comédia do desentendimento, quando as três mulheres falam a respeito do que faziam "lá em Cambuquira" e revelam que, entre outras coisas, catavam tiririca. Sarah tenta repetir o significante ("Ti-ri-ri-cá") e, quem sabe, captar algum significado. As irmãs tentam explicar, através de berros e de mímica, que é uma erva daninha; por sua vez, Sarah conclui: "vous êtes ti-ri-ri-cá!"

Noutra sequência (AMÉLIA, 2000, cap.9), o porco trazido de Cambuquira volta à cena como prato principal de um piquenique à francesa, para o qual a atriz francesa convida as três "Valquírias." Diante de uma Sarah horrorizada, com talheres e pratos de porcelana na mão, as três destrincham e devoram o porco utilizando as próprias mãos. Sarah se desespera e repente inutilmente:

Não! Esperem. Deixe explicar. Você segura a faca com esta mão. Preste atenção em mim (...) Usem a faca com a mão direita e o garfo com a esquerda. Olhem para mim, por favor, (...) Amélia adorava jantar com

\footnotetext{
${ }^{9}$ Sarah refere-se às três com esse epíteto: "as Valquírias de Cambuquira" AMÉLIA, 2000, cap.10) Na mitologia céltica, a palavra original do Nórdico antigo, Valkyrja, significa "a que escolhe os mortos." Entidades sobrenaturais relacionadas diretamente com marcialidade, a sua associação com o destino dos guerreiros mortos na batalha remete a uma tradição mítica muito anterior aos Vikings, vinculada aos antigos germanos. Conferir: LANGER, Johnni. As Valquírias na Mitologia Viking: um estudo diacrônico. Revista Brathair de Estudos Celtas e Germânicos, v. 1, n. 4, p. 52-69, 2004.
} 
champanhe. Precisam aprender. Garanto que aprendem, com a mão esquerda e a direita. Observem e tentem. Tentem!

Irritada, Maria Luisa replica: "Amélia gostava era de carne de porco!" Civilização versus Barbárie? Conceitos construídos, quiçá inventados (HOBSBAWM, 1984, p.9-23), que refletem a consciência que o Ocidente tem de si mesmo e do Outro. Conforme afirma Norberto Elias:

Poderíamos até dizer: a consciência nacional. Ele [o conceito de civilização] resume tudo em que a sociedade ocidental dos últimos dois ou três séculos se julga superior a sociedades mais antigas ou a sociedades contemporâneas "mais primitivas". Com essa palavra, a sociedade ocidental procura descrever o que lhe constitui o caráter especial e aquilo de que se orgulha: o nível de sua tecnologia, a natureza de suas maneiras, o desenvolvimento de sua cultura científica ou visão de mundo, e muito mais. (ELIAS, 1994, v.1, p.23).

Estado de coisas, espelhado ao longo de todo filme, que aponta, para dizer com Silviano Santiago, para a experiência da colonização, experiência narcísica na qual o outro deve ser assimilado à imagem e semelhança do conquistador, confundindo-se com ela e perdendo, portanto, a condição de sua alteridade. (1982, p.15).

Como trapacear essa ordem colonial? Como lidar com a questão da dependência cultural? A literatura, o cinema e o discurso crítico brasileiros em diferentes momentos retomaram a antropofagia como conceito operatório para lidar com a questão da dependência cultural, para desconstruir a lógica colonial. No Romantismo e no Modernismo, no que se refere à literatura; durante o cinema novo - como nos emblemáticos Macunaíma, de Joaquim Pedro de Andrade, e Como era gostoso o meu francês, de Nelson Pereira dos Santos - no pensamento de críticos como Haroldo de Campos e Silviano Santiago. ${ }^{10}$

Em Amélia, não é diferente. "Como era gostosa a nossa francesa?" Sim e não. Voltemo-nos para as últimas sequencias do filme (AMÉLIA, 2000, cap. 13). As três mulheres de cambuquira invadem o quarto de Sarah para exigir seus direitos - "E o dinheiro? Onde é que ta o dinheiro?" - e temos o grande embate - uma espécie de dueto, composto de diferentes árias, afinal, não se pode esquecer de que a peça a ser encenada por Sarah é a Tosca, de Victorien Sardou, que serviria de mote para a famosa ópera de Puccini (1900). Recorto alguns trechos da fala da personagem Sarah Bernhardt:

Calem-se e se afastem! (...) Três porcas imundas. Sempre a me farejar para me devorar aos poucos! Para talvez adquirir minha grandeza, meu saber, minha força, minha arte, minhas rendas, meus perfumes e meu dinheiro (...). Mas é inútil. Vocês vão me engolir toda crua e sua voracidade grosseira não vos alimentarão jamais de civilização da qual sou testemunha viva. Porque foi lá que fui educada, lá na França, onde aprendi a sabedoria, a inteligência, o dom da ação, o sentido das palavras, o valor do pensamento! Foi lá! Aqui,

\footnotetext{
${ }^{10}$ Entre outros textos, cito: CAMPOS, Haroldo. Da razão antropofágica: diálogo e diferença na cultura brasileira. In: _. Metalinguagem e outras metas. São Paulo: Perspectiva, 1992. p. 231-253; SANTIAGO, Silviano. Apesar de dependente universal. In: _. Vale quanto pesa: ensaios sobre questões político-culturais. Rio de Janeiro: Paz e Terra, 1982. p.13-24; SANTIAGO, Silviano. Uma literatura nos trópicos. São Paulo: Perspectiva, 1978; SANTIAGO, Silviano. Oswald de Andrade: elogio da tolerância racial. In: conversa: ensaios literários. Belo Horizonte: Editora UFMG, 2006.133-145. Ora (direis) puxar
} 
nada! Pouco me importa agora a humildade ou o orgulho. Minha boca cuspirá tudo o que me fizeram engolir de maldade! Meu coração será libertado e minha memória apagará, um a um, cada detalhe de seus rostos monstruosos!

Tem-se na fala de Sarah Bernhadt uma primeira nuança da noção de antropofagia, e que, infelizmente, é a mais cristalizada pelo pensamento ocidental: a devoração (a)crítica do Outro, operada pela necessidade de assimilar o que de bom a cultura estrangeira tem a oferecer. Sendo, no caso específico, o europeu, o outro desejado para ser deglutido, supõe-se, portanto, uma admiração pelo objeto devorado e a assimilação de suas qualidades. Por outro lado, a antropofagia oswaldiana permite que se desloque e embaralhe os pólos tradicionalmente conhecidos como dentro e fora, regional e global. Conforme adverte Eneida Maria de Souza:

Ao se desvincular o conceito de exterior do que é próprio do estrangeiro e incorporá-lo aos elementos que representam o estranho para a cultura branca, como o índio e o negro, consegue-se ampliar a relação entre interior/exterior. [...] na busca de uma identidade que não se circunscreve à essência do nativo, mas à necessidade de criá-la, sem a imitação do modelo estrangeiro. (2007, p.53)

Diante das últimas palavras de Sarah Bernhadt: “(...) Olhem para mim e olhem para vocês! Vocês são inação, preguiça e destruição!" A resposta eufórica e positiva de Francisca é:

De Gonçalves Dias, poeta maranhense, I JUCA PIRAMA [e recita os seguintes versos do poeta transcritos abaixo]

Meu canto de morte,

Guerreiros, ouvi:

Sou filho das selvas,

Nas selvas cresci;

Guerreiros, descendo

Da tribo tupi.

Da tribo pujante,

Que agora anda errante

Por fado inconstante,

Guerreiros, nasci;

Sou bravo, sou forte,

Sou filho do Norte;

Meu canto de morte,

Guerreiros, ouvi.

E tem mais: "Colombo! fecha a porta dos teus mares!" [numa referência ao "Navio negreiro" de Castro Alves]

Poder-se-ia dizer que a escolha de Francisca e, obviamente, de Ana Carolina"I-Juca Pirama" e "Navio negreiro", capítulos culminantes da "rapsódia nacional" (ANDRADE, 1974, p.115) - é pontual. Afinal, a recuperação dos versos de dois de nossos mais importantes poetas românticos - Gonçalves Dias e Castro Alves - permite-nos atentar para o fato de que o Romantismo brasileiro, assim como o europeu, abraçou uma variedade de respostas contraditórias às questões políticas, econômicas e estéticas que atravessaram o século XIX. Tal cenário variegado também se aplica ao corpo dos textos indianistas nos quais 
essas contradições também foram encenadas, em representações muitas vezes marcadas por um senso de ruptura. O texto indianista mais celebrado de Gonçalves Dias, em que o guerreiro, "aquele que deve morrer", inicialmente, tomado por fraco, mas que prova a sua coragem e faz jus ao ritual de devoração, representa, nas palavras de David Treece, "o ponto culminante desse drama - a desintegração da família e da comunidade, o exílio do indivíduo e sua busca em recuperar o sentimento de solidariedade e pertencimento dentro da integridade da cultura tribal." (TREECE, 2008, p.187). No poema, publicado em 1851, o ritual antropofágico configura-se como estratégia de reconciliar e reintegrar a essência cultural indígena por meio do mito que se atualiza; "Em tudo o rito se cumpra!" (DIAS, 1996, p.83).

Tanto "I Juca Pirama" quanto "Navio negreiro", metaforicamente, chamam a atenção para a necessidade de uma nova colonização do país, explicitada por Silviano Santiago em sua leitura da poesia de Oswald de Andrade: "diferente da concepção de processo e evolução históricos, diferente da concepção então vigente entre historiadores e sobretudo muito diferente da que foi dominante entre os nossos historiadores oficiais (...)", (SANTIAGO, 2006, p.135-136), uma colonização outra, decidida pela vontade expressa dos agentes sociais, em um movimento de interiorização das culturas indígena e negra, elementos constitutivos de nossa formação e que, por definição, escapam ao devir da razão histórica. (SANTIAGO, 2006, p.139).

É durante a representação de Tosca que a fratura é literalmente exposta (AMÉLIA, 2000, cap.13). No meio da peça, Sarah esquece o texto - perdida em sua própria terra, nem Paris, nem Europa, mas o teatro, em um dado momento do filme ela afirma: [referindo-se ao palco] "É aqui o meu país" (AMÉLIA, 2000, cap. 8) - e ao final do espetáculo, na grande cena, em que a personagem Tosca se joga do parapeito do Castelo de Sant' Ângelo,

Do alto do castelo, Sarah olha para o fundo do palco, para as almofadas que a protegeriam quando de lá se jogasse (almofadas que as brasileiras confeccionaram), e vê - o horror - que elas retirarão o solo macio para o fingimento da morte. As irmãs de Amélia puxam as almofadas, restando apenas o duro terreno das costas da coxia. Sarah poderia escolher e não saltar. Mas não poderia. Escolhe o que tem de escolher. Escolhe o Teatro; ou seja, o inevitável - a arte, a dor, a ruptura do corpo. Joga-se (acontecimento absoluto, terrivelmente estético e grandiloquente: gritar, pois). Talvez não. (SANTOS, 2002)

Se a noção de antropofagia, cristalizada, a partir de relatos como o de Hans Staden e ode Jean Léry, o índio devora o europeu para assimilar sua força e conhecimentos, na última sequência de Amélia (2000, cap.14), Sarah Bernhadt surge, no palco, em Paris, em 1915. Ao lado de uma onça cenográfica, a atriz, vestida de negro e adornada com penas de aves tropicais, recita, em seu francês melódico, "I Juca Pirama." A câmera passeia pelo palco, os figurantes encenam, à francesa, o poema, com seu cenário e índios carnavalescos. Nesse passeio, a câmara deixa entrever, entre as pregas do vestido da atriz, uma prótese que lhe substitui a perna amputada. Por fim, em meio aos figurantes franceses, trajando-se de índias, as três cambuquirenses dançam e repetem quase em murmúrio: "sou bravo, sou forte, sou filho do norte." A cenografia aponta para uma representação caricatural do ritual de canibalismo, talvez lido como prova da "barbárie primitiva do índio," num diálogo tecido por uma visão deslumbrada e atônita, em que não se apreende o significado do gesto do outro. Antropofagia às avessas, a francesa devora as mineiras e as incorpora ao seu "coro de contentes." Porém, no momento dos aplausos, pouco antes de se fecharem as cortinas, o áudio 
nos traz uma última aresta irônica que ressignifica e realoca algumas das questões identitárias colocadas ao longo do filme: Pena Branca e Xavantinho interpretam a "Canção do exílio", de Gonçalves Dias, acompanhados da viola de Almir Sater. Se "I-Juca Pirama" é submetido ao francês, na performance de Sarah, ficamos, por fim, - a "Canção do exílio", cantada por Pena Branca e Xavantinho, acompanha os letreiros finais do filme (AMÉLIA, 2000, cap.15) - com o "canto romântico" incorporado à viola sertaneja, em um processo de mescla que, longe de sintetizar num espaço de resolução diferentes experiências, aponta para o caráter relacional dos processos de construção identitária. Na verdade, o que filme de Ana Carolina nos lega é a compreensão de que, para dizer com o pensador peruano Antonio Cornejo Polar, "[nossa] identidade é também a desestabilizante identidade do outro, espelho ou sombra a que se incorpora obscura, dilacerada e conflituosamente, como opção de alheamento ou de plenitude." (2000, p.271).

\section{REFERÊNCIAS}

ALMEIDA JR., J. M. G. de. A legislação e o cinema brasileiro. Brasília: Consultoria Legislativa da Câmara dos Deputados, 2001. (Estudos). Disponível em: <http://biblioteca.planejamento.gov.br/biblioteca-tematica-1/textos/educacao-cultura/texto-72013-a-legislacao-e-o-cinema-brasileiro.pdf>. Acesso em: 08 jul. 2012.

AMÉLIA. Direção: Ana Carolina. São Paulo: Vídeo Filmes, ano da produção: 2000. 1 DVD (126 min. aprox.), NTSC, Color., Son.

ANDRADE, M. Aspectos da literatura brasileira. 5. ed. São Paulo: Martins, 1974.

BARTHES, R. O rumor da língua. In: __ O O rumor da língua. 2. ed. São Paulo: Companhia das Letras, 2004. (Coleção Roland Barthes). p. 93-97.

BIBLIOTECA da ECA/USP. Blog no WordPress.com. Disponível em: < http://bibliotecadaeca.wordpress.com/2011/06/16/citando-filmes/>; Acesso em 11 jul. 2012.

CAROLINA, A. Programa Roda Viva. TV Cultura. Entrevista concedida a Hector Babenco; Ivana Bentes; Evaldo Mocarzel; Caio Túlio Costa; Suzana Amaral; Celso Masson; Aníbal Massaini, e Christian Petermann e exibida em 19 de Nov. 1994. Disponível em: http://www.rodaviva.fapesp.br/materia_busca/332/Ana\%20Carolina/entrevistados/ana_carolin a_1994.htm; Acesso em: 26 jul. 2010.

Entrevista - Caderno B. Jornal do Brasil, Rio de Janeiro, 8 dez. 1987. Apud. In: LOBATO, Ana Lucia. Cineasta do Mês: Ana Carolina. Cinemin, Rio de Janeiro, n. 77, p.41, Jun. 1992.

CAMPOS, H. Da razão antropofágica: diálogo e diferença na cultura brasileira. In:

Metalinguagem e outras metas. São Paulo: Perspectiva, 1992. p. 231-253.

Arte pobre, tempo de pobreza, poesia menos. In: . Metalinguagem e outras metas. São Paulo: Perspectiva, 1992.

CORNEJO POLAR, A. Condor voa: literatura e cultura latino-americanas. Org. Mario J. Valdés. Trad. Ilka Valle de Carvalho. Belo Horizonte: Ed. UFMG, 2000.

DIAS, G. Poemas. Sel. Intr. Notas de Péricles Eugênio da Silva Ramos. 12. ed. Rio de Janeiro: Ediouro, 1996.

ELIAS, N. O processo civilizador: uma história dos costumes. Trad. Ruy Jungmann. Rio de Janeiro: Jorge Zahar Editor, 1994. v.1.

GALVÃO, W. N. Metamorfoses do sertão. Estudos Avançados, São Paulo, v. 18, n. 52, dez. 2004. Disponível em: < http://www.scielo.br/scielo.php?pid=S010340142004000300024\&script=sci_arttext >; Acesso em: 14 jun. 2006. 
HOBSBAWM, E. J. Introdução: A invenção das tradições. In: HOBSBAWM, Eric J; RANGER, Terence. A invenção das tradições. Trad. Celina Cardim Cavalcante. Rio de Janeiro: Paz e Terra, 1984. (Pensamento crítico, v.55), p.9-23.

LANGER, J. As Valquírias na Mitologia Viking: um estudo diacrônico. Revista Brathair de Estudos Celtas e Germânicos, v. 1, n. 4, p. 52-69, 2004.

MORCAZEL, E. Ana Carolina Teixeira Soares: cineasta brasileira. São Paulo: Imprensa Oficial do Estado de São Paulo, 2010. (Coleção Aplauso. Série perfil).

NAGIB, L. O cinema da retomada - depoimentos de 90 cineastas dos anos 90. São Paulo: Editora 34, 2002. v. 1.

PIGLIA, R. Memoria y tradición. In: CONGRESSO INTERNACIONAL ABRALIC, 2, 1990, Belo Horizonte. Anais.... Belo Horizonte:UFMG, v. 1, 1990, p. 60-66 p. 61.

Una propuesta para el nuevo milenio. Margens: caderno de cultura, Belo Horizonte, n.2, p.1-3 out.2001.

ROCHA, G. Uma estética da fome. Arte em revista, São Paulo, v.1, n.1, p-15-17, 1979.

ROSENFELD, A. Cinema: arte \& indústria. In: Cinema: arte \& indústria. São Paulo: Perspectiva, 2002. (Debates), p.33-47.

SANTIAGO, S. Navegar é preciso, viver. In: NOVAES, Adauto (org.). Tempo e história. São Paulo: Companhia das Letras; Secretaria Municipal de Cultura, 1992. p. 463-472. Apesar de dependente universal. In: Vale quanto pesa: ensaios sobre questões político-culturais. Rio de Janeiro: Paz e Terra, 1982. p. 13-24

Uma literatura nos trópicos. São Paulo: Perspectiva, 1978. Oswald de Andrade: elogio da tolerância racial. In:

Ora (direis) puxar conversa: ensaios literários. Belo Horizonte: Editora UFMG, 2006. p.133-145.

SANTOS, R. C. dos. Amélia de Ana Carolina - Senhores, Eu vi. In: Cátedra Padre Antônio Vieira de Estudos Portugueses. Revista Semear, n. 6. 2002. Disponível em: <http://www.letras.pucrio.br/Catedra/revista/6Sem_10.html> Acesso em: 01 abr. 2010.

SOUZA, E. M. de. Crítica Cult. Belo Horizonte: Editora UFMG, 2002.

SÜSSEKIND, F. Paciência e ironia: sobre o cinema de ficção de Ana Carolina. In: A

voz e a série. Rio de Janeiro; Belo Horizonte: Sette Letras; UFMG, 1998. p. 59-68.

TREECE, D. Exilados, aliados, rebeldes: o movimento indianista, a política indigenista e o estado-nação imperial. São Paulo: Nankin; Edusp, 2008.

Verbete AMÉLIA. In: NOVO Aurélio. O Dicionário da Língua Portuguesa. Século XXI. Rio de Janeiro: Nova Fronteira, 1999, p. 119.

Verbete AMÉLIA. In: HOUAISS Antônio e VILLAR Mauro de Salles. Dicionário Houaiss da Língua Portuguesa. Instituto Antônio Houaiss de Lexicografia e Banco de Dados da Língua Portuguesa, Rio de Janeiro: Objetiva, 2001. p. 186.

Recebido em: 18/07/12

Aprovado em: 20/10/12 